\title{
Serum C-Reactive Protein/Albumin Ratio in Rheumatoid Arthritis and its Relationship With Disease Activity, Physical Function, and Quality of Life
}

\author{
İsmihan SUNAR (D), Şebnem ATAMAN (1) \\ Department of Physical Medicine and Rehabilitation, Division of Rheumatology, Ankara University School of Medicine, Ankara, Turkey
}

\begin{abstract}
Objectives: This study aims to evaluate the relationship between C-reactive protein (CRP)/albumin ratio (CAR) and disease activity, quality of life (QoL), and physical function in rheumatoid arthritis (RA).

Patients and methods: A total of 121 RA patients (22 males, 99 females; mean age $57.6 \pm 11.2$ years; range, 32 to 85 years) applying to Ankara University School of Medicine Rheumatology Outpatient Clinic between January 2019 and February 2019 were included in this cross-sectional study. The inclusion criteria were fulfilling the American College of Rheumatology/European League Against Rheumatism 2010 RA classification criteria, being over 18 years and accepting to participate in the study. Demographic and clinical parameters including serum erythrocyte sedimentation rate (ESR), CRP and albumin levels were recorded. Disease activity was measured using Disease Activity Score 28 (DAS28)-ESR. General health, fatigue, and pain were questioned by means of a $100 \mathrm{~mm}$ visual analog scale (VAS). The QoL was assessed with the Rheumatoid Arthritis Quality of Life (RAQoL) Questionnaire. The functional status was determined using the Health Assessment Questionnaire (HAQ).

Results: Rheumatoid factor (RF) was positive in $56.2 \%$ of the patients. The median ESR was $19.0 \mathrm{~mm} /$ hour (interquartile range [IQR]: 19.5) and median CRP was 5.6 (IQR: 9) mg/L. The median CAR was 1.3 (IQR: 2.1) and median DAS 28-ESR was 3.6 (IQR: 1.5). There was a significant but weak correlation between CAR and DAS28-ESR ( $p<0.001$, Spearman's correlation coefficient $[r s]=0.327$ ). Moreover, CAR was positively correlated with ESR, CRP, and VAS physician's global assessment $\left(p<0.001, r_{s}=0.497 ; p<0.001, r_{s}=0.987, p<0.001, r_{s}=0.401\right.$, respectively). However, no correlation was observed between CAR, HAQ, and RAQoL. In the RF positive group, there was a significant but weak correlation between CAR and RF titers $\left(p=0.016, r_{s}=0.292\right)$. Conclusion: We observed a positive but weak correlation between CAR and DAS28-ESR, ESR, and the RF titer. Further studies are warranted to investigate the role of CAR in RA.

Keywords: Albumin, C-reactive protein, quality of life, rheumatoid arthritis.
\end{abstract}

Rheumatoid arthritis (RA) is a systemic autoimmune disease characterized by synovial inflammation eventually leading to joint deformities. It has a symmetric polyarticular involvement of the hands and feet as well as certain extra-articular manifestations. ${ }^{1}$ Early diagnosis and treatment of RA can restrain or decelerate joint damage in up to $90 \%$ of patients. ${ }^{2}$ Therefore, both early diagnosis and strict follow-up are mandatory for preventing irreversible disability. In addition to physical examination and clinical evaluation, the biomarkers are important in diagnosis and followup of RA. The current classification criteria of RA partially rely on acute phase reactants (APRs) such as C-reactive protein (CRP), erythrocyte sedimentation rate (ESR) and autoantibodies including rheumatoid factor (RF) and antibodies against citrullinated proteins (ACPAs). ${ }^{3}$ "Treating

Received: February 19, 2019 Accepted: July 21, 2019 Published online: February 07, 2020

Correspondence: İsmihan Sunar, MD. Ankara Üniversitesi Tıp Fakültesi, Fiziksel Tıp ve Rehabilitasyon Anabilim Dalı, Romatoloji Bilim Dalı, 06590 Çankaya, Ankara, Türkiye. Tel: +90 256 - 2132079 e-mail: dr.ismihan@gmail.com of Life. Arch Rheumatol 2020;35(2):247-253. 
to target" strategy in RA recommends measuring disease activity regularly and adjusting therapy accordingly to optimize the outcome. The primary goal is capturing a state of clinical remission by assessing the disease activity with use of composite indices to monitor the severity of the disease. The disease activity score 28 (DAS28ESR) is the most widely applied instrument in both clinical trials and daily practice. ${ }^{4}$ It contains tender and swollen joint counts (TJC, SJC) on a total of 28 joints, patient's global assessment of general health on a $100 \mathrm{~mm}$ visual analog scale (VAS global $_{\text {, }}$, and ESR. Other commonly used composite indices include Simplified Disease Activity Index (SDAI) and Clinical Disease Activity Index (CDAI). ${ }^{5}$ Patient-reported outcome (PRO) measures and evaluation of physical functions are also important adjunct disease activity indicators. ${ }^{6}$

Acute phase reactants are important in both diagnosis and follow-up. The inclusion of CRP and ESR into composite indices is fully justified by their face and content validity. ${ }^{7}$ Of these, serum CRP is a representative APR which is mainly synthesized by hepatocytes under the control of proinflammatory cytokines, particularly interleukin-6 (IL-6). ${ }^{8}$ In a study on patients with RA, it was stated that serum CRP was the most useful biochemical marker for evaluation of disease activity among various APR tests including ESR, haptoglobin, ferritin, and fibrinogen. ${ }^{9}$ CRP to albumin ratio (CAR) is a novel inflammatory marker which may not only present the inflammatory aspect, but also the nutritional status. CAR was shown to have a prognostic value in lung cancer with significant correlation to overall survival. ${ }^{10}$ In a recent retrospective study on 160 patients with RA and 159 healthy controls, CAR was found to be higher than controls and positively correlated with DAS28-ESR. Therefore, CAR was proposed to be a novel inflammatory marker for monitoring disease activity in RA. ${ }^{11}$

As far as we are concerned, the association between CAR and other clinical parameters including physical status and quality of life (QoL) in patients with RA has not been investigated in any cross-sectional design before. Therefore, in this study, we aimed to evaluate the relationship between CAR and disease activity, QoL, and physical function in RA.

\section{PATIENTS AND METHODS}

In this cross-sectional study, 121 patients with RA (22 males, 99 females; mean age 57.6 \pm 11.2 years; range, 32 to 85 years) applying to Ankara University School of Medicine Rheumatology Outpatient Clinic for their regular follow-up visits between January 2019 and February 2019 were included randomly. The inclusion criteria were satisfying the American College of Rheumatology/ European League Against Rheumatism 2010 RA classification criteria, being over 18 years and approving to participate in the study. Exclusion criteria were having malignancy, pregnancy, lactation, malignant hematologic diseases, other chronic inflammatory diseases, active hepatitis, chronic liver or renal insufficiency. The study protocol was approved by the Ankara University Ethics Committee (decision number: 1-12-2019, date: 14.01.2019). A written informed consent was obtained from each patient. The study was conducted in accordance with the principles of the Declaration of Helsinki.

Physical examination to ascertain number of tender and swollen joints was performed by a rheumatologist. VAS global, physician's global assessment $\left(\mathrm{VAS}_{\mathrm{dr}}\right.$ ), patients' pain assessment (VAS $\left.{ }_{\text {pain }}\right)$, and patients' fatigue assessment

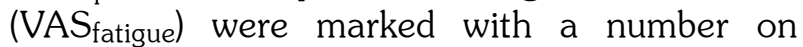
1-100 mm VAS with higher numbers indicating worse status. The DAS28-ESR score is calculated using the number of tender joints or swollen joints, VAS $_{\text {global, }}$ and ESR following the formula: 0.56 * $\sqrt{ }(\mathrm{TJC} 28)+0.28 * \sqrt{ }(\mathrm{SJC} 28)+0.70 * \ln (\mathrm{ESR})+$ 0.014 * VAS (General Health). ${ }^{4}$ A DAS28-ESR score above 5.1 indicates high disease activity, whereas a DAS28-ESR score between 3.2 and 5.1 means moderate activity, and $<3.2$ is associated with low disease activity-remission. ${ }^{12}$

Blood analyses were performed on venous samples in the morning. Serum ESR was measured by Sistat device with infrared barrier technique (Sistat Ltd., Ankara, Turkey). Serum CRP was measured by immunoturbidimetric method with Beckman Coulter AU5800 device (IDS Co Ltd., Japan) with a normal range of $0-5 \mathrm{mg} / \mathrm{L}$. Albumin levels were analyzed by spectrophotometric method depending on the principle of formation of green colored complexes with bromocresol using the Beckman Coulter AU5800 device (IDS Co Ltd., Japan). 
RF was measured with immunoturbidometric method with Beckman Coulter AU5800 device (IDS Co Ltd., Japan) and levels above $14 \mathrm{IU} / \mathrm{mL}$ were considered positive.

The QoL was assessed with Rheumatoid Arthritis Quality of Life(RAQoL) Questionnaire..$^{13,14}$ The RAQoL comprises 30 items with a simple yes or no response respectively corresponding to 1 or 0 points. Total score ranges from 0 to 30 and higher scores indicate poorer QoL. ${ }^{13}$

The functional status was determined using the Health Assessment Questionnaire (HAQ). The $\mathrm{HAQ}$ is a measure developed for determination of functional status in patients with arthritis. It consists of a total of 20 items in eight subgroups of functioning which are dressing, rising, eating, walking, hygiene, reaching, gripping and usual activities. Each item is scored from 0 to 3, which respectively represent no difficulty, some difficulty, much difficulty, and inability. The highest score of each subgroup determines the score for each category but may also be affected by usage of any assistive devices or aid. The overall score ranges from 0 to 3 with higher scores indicating worse physical function. . $^{15,16}$

\section{Statistical analysis}

The SPSS version 11.5 software (SPSS Inc., Chicago, IL, USA) was used for the analyses. The minimum sample size was calculated according to the results of the article by Yang et al. ${ }^{11}$ in which they reported a correlation coefficient of $r=0.645, p<0.001$ between CAR and DAS28-ESR. Since the primary aim of the present study was to evaluate the association between CAR and DAS 28-ESR, assuming a modest correlation between these two parameters, we calculated the sample size with $95 \%$ power and $\alpha=0.05$ error rate and found a minimum number of 121 patients. G*Power 3.1.9.2 package program (HeinrichHeine-Universität, Düsseldorf, Düsseldorf, Germany) was used for determination of the sample size. Descriptive variables were given as percentages, mean, median, standard deviation, and interquartile range (IQR). Whether the data were distributed normally was assessed by the Kolmogorov-Smirnov test and histograms. Mann-Whitney U test was used to investigate the significance of difference of DAS28-ESR and CAR between biologic and disease-modifying anti- rheumatic drug (DMARD) users. Kruskal-Wallis test was used to observe any difference of CAR between remission-low, moderate, and high disease activity groups according to DAS28-ESR. Spearman's correlation coefficient ( $\mathrm{rs}$ ) was used for correlations between non-parametric data. A $p$ value $<0.05$ was considered statistically significant.

\section{RESULTS}

Of the 121 RA patients, $84.3 \%$ were married and $15.7 \%$ were single. Forty-three percent of them were primary and secondary school graduates while 30\% were high school and 6.6\% were university graduates. Sixty-five percent were housewives while 15\% were employed and 20\% were unemployed or retired. Of the patients, $64.5 \%$ used synthetic DMARDs, and 35.5\% were on biologic DMARD treatment. RF was positive in $56.2 \%$ of the patients. Sixty-seven percent of the patients complained of morning stiffness with a mean duration of $31.2 \pm 33.6$ minutes. The median ESR was $19 \mathrm{~mm} /$ hour (IQR: 19.5) and median CRP was 5.6 (IQR: 9) $\mathrm{mg} / \mathrm{L}$. The CAR was 1.3 (IQR: 2.1), median albumin was 4.3 (IQR: 0.4) $\mathrm{g} / \mathrm{dL}$, and median DAS28-ESR was 3.6 (IQR: 1.5) (Table 1). According to the DAS28-ESR, 38\% of patients had low disease activity or were in remission, $50.4 \%$ had moderate disease activity, and $11.6 \%$ had high disease activity. When patients were classified according to their medications such as synthetic and biological DMARDs, no difference in terms of CAR and DAS28-ESR was found between groups ( $p=0.937$ and $p=0.918$, respectively).

There was a significant but weak correlation ${ }^{17}$ between CAR and DAS28-ESR $(p<0.001$, $r_{s}=0.327$ ) while no correlation between CAR and VAS $_{\text {global }}$, VAS pain, VAS fatigue, HAQ and RAQoL was detected. Whether the magnitude of correlation fluctuates between remission-low, medium and high activity groups was investigated. We observed that there was a significant but weak correlation between CAR and DAS28-ESR in patients with moderate and high disease activity $\left(p=0.053, r_{s}=0.224\right)$. CAR also exhibited significant positive correlations with ESR, CRP, and VAS $_{\text {dr }}\left(p<0.001, r_{s}=0.497 ; p<0.001\right.$, $r_{s}=0.987 ; p<0.001, r_{s}=0.401$, respectively). There 
Table 1. Demographic and clinical characteristics of patients $(\mathrm{n}=121)$

\begin{tabular}{|c|c|c|c|c|}
\hline & $\%$ & Median & IQR & Mean \pm SD \\
\hline Age (years) & & & & $57.6 \pm 11.2$ \\
\hline $\begin{array}{l}\text { Gender } \\
\text { Female }\end{array}$ & 81.8 & & & \\
\hline Drug (bDMARD) & 34.5 & & & \\
\hline $\mathrm{ESR}(\mathrm{mm} / \mathrm{h})$ & & 19 & 19.5 & \\
\hline $\mathrm{CRP}(\mathrm{mg} / \mathrm{L})$ & & 5.6 & 9 & \\
\hline Albumin (g/dL) & & 4.3 & 0.4 & \\
\hline RF (positive) & 56.2 & & & \\
\hline CAR & & 1.3 & 2.1 & \\
\hline DAS28 & & 3.6 & 1.5 & \\
\hline VAS $_{d r}$ & & 40 & 30 & \\
\hline VAS $_{\text {global }}$ & & 50 & 35 & \\
\hline VAS $_{\text {fatigue }}$ & & 70 & 30 & \\
\hline VAS $_{\text {pain }}$ & & 60 & 30 & \\
\hline HAQ & & 1 & 1.25 & \\
\hline RAQoL & & 14 & 17 & \\
\hline \multicolumn{5}{|c|}{ 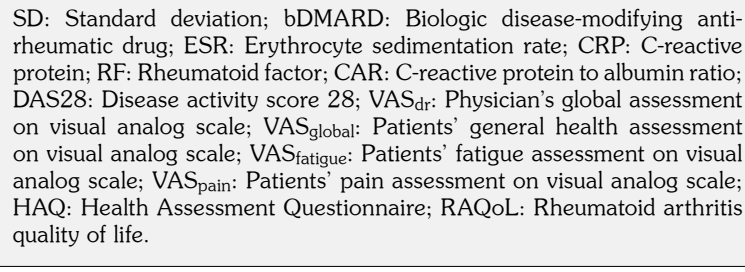 } \\
\hline
\end{tabular}

Table 2. C-reactive protein/albumin ratio and its correlation with other clinical parameters

\begin{tabular}{lcc}
\hline & \multicolumn{2}{c}{ CAR } \\
\cline { 2 - 3 } DAS28 & $p$ & $\mathrm{r}_{\mathrm{s}}$ \\
HAQ & $<0.001$ & 0.327 \\
RF $^{*}$ & 0.155 & 0.130 \\
RAQoL & 0.016 & 0.292 \\
VAS $_{\text {global }}$ & 0.295 & -0.096 \\
VAS $_{\text {pain }}$ & 0.900 & 0.012 \\
VAS $_{\text {fatigue }}$ & 0.886 & 0.013 \\
VAS $_{\text {dr }}$ & 0.556 & 0.054 \\
ESR $_{\text {mm/h) }}$ & $<0.001$ & 0.401 \\
CRP (md/L) & $<0.001$ & 0.497 \\
\hline
\end{tabular}

CAR: C-reactive protein to albumin ratio; $r_{\mathrm{s}}$ : Spearman's correlation coefficient; DAS28: Disease activity score 28; HAQ: Health Assessment Questionnaire; RF: Rheumatoid factor; RAQoL: Rheumatoid arthritis

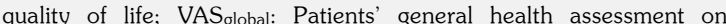
visual analog scale; $V S_{\text {pain: }}$ Patients' pain assessment on visual analog scale; VAS fatigue: Patients' fatigue assessment on visual analog scale; $V_{\text {AS }}$ : Physician's global assessment on visual analog scale; ESR: Erythrocyte sedimentation rate; CRP: C-reactive protein; * In rheumatoid factor positive group. were positive significant correlations between DAS28-ESR and HAQ, VAS global, VAS fatigue, VAS $_{\text {pain }}$, and VAS $\mathrm{dr}_{\mathrm{dr}}\left(\mathrm{p}<0.001, \mathrm{r}_{\mathrm{s}}=0.579, \mathrm{p}<0.001\right.$, $r_{s}=0.391, p<0.001, r_{s}=0.427, p<0.001, r_{s}=0.419$, $\mathrm{p}<0.001, \mathrm{r}_{\mathrm{s}}=0.711$, respectively) and negative significant correlations between DAS28-ESR and RAQoL, and albumin level $\left(p<0.001, r_{s}=-0.355\right.$; $p=0.023, r_{s}=-0.207$, respectively) (Table 2 ).

In the RF positive group $(n=68)$, there was a significant but weak positive correlation between CAR and RF titers $\left(p=0.016, r_{s}=0.292\right)$. Also, CAR was significantly different between high, medium and low-remission disease activity groups $(p=0.008)$. Post hoc analyses revealed that CAR was significantly higher in patients with DAS28-ESR $>5.1$ compared to those with low activity and remission $(p=0.011)$.

\section{DISCUSSION}

C-reactive protein/albumin ratio is named among the inflammation-based prognostic scores which further include the neutrophil lymphocyte ratio, platelet lymphocyte ratio, and modified Glasgow prognostic score. CAR has been reported to be a significant predictor of worse overall survival in several cancer types, ${ }^{18-20}$ Crohn's disease, ${ }^{21}$ vasculitides,${ }^{22}$ and critically ill patients. Moreover, CAR was reported to be an independent predictor of mortality and to perform better than CRP alone. ${ }^{23,24}$ Serum albumin, the most abundant protein of the blood plasma, ${ }^{25}$ is not only an indicator of nutritional status but also a negative APR contributing to CRP in assessing inflammation. A retrospective study on 170 patients with antineutrophil cytoplasmic antibody-associated vasculitis proposed that CAR at diagnosis was an independent predictor of all-cause mortality. In a recent retrospective study including 32 patients with Takayasu arteritis and 32 healthy controls, CAR was found to be significantly correlated with disease activity, CRP and ESR levels. ${ }^{26}$ This study is among the first studies to evaluate the role of CAR in rheumatic diseases. Similar to their results, we found positive correlations between CAR and RA disease activity determined by DAS28-ESR, ESR, and CRP.

In a retrospective study on 160 patients with RA and 159 healthy controls, CAR was found 
to be positively correlated with DAS28-ESR. Authors concluded that CAR could be a simple inflammatory parameter in RA with a potential value for monitoring RA disease activity. ${ }^{11}$ Similarly, we observed a significant but weak correlation between CAR and DAS28-ESR. On the other hand, no correlation between CAR and HAQ and RAQoL was seen. Although we observed positive significant correlations between DAS28-ESR and HAQ, VAS global, VAS fatigue, and $\mathrm{VAS}_{\text {pain }}$; and a negative correlation between DAS 28-ESR and RAQoL, CAR could not detect these available associations which were also established in several studies before. ${ }^{27,28}$ This may be a factor limiting the role of CAR as a disease activity marker in RA which have certain impacts on function and QoL.

In evaluation of a patient with RA, DAS28, a reliable and valid index, is one of the most commonly applied composite disease activity measures. If computing DAS28 is considered time-consuming to some extent in busy settings due to dependence on an online calculator, PRO scales may be preferred. Routine Assessment of Patient Index Data 3 (RAPID3) and Rheumatoid Arthritis Disease activity index-5 (RADAI-5) may be named among these outcome measures. Significant correlations between RADAI- 5 and DAS28 and CDAI, and RAPID3 and DAS28 were depicted in several studies. ${ }^{29,30}$ These indices have been suggested to provide benefit by saving time in daily practice. Also, they help avoiding the possible physician variations and require minimal professional time for assessment of joints. ${ }^{31}$ Similar to PROs, CAR may be used in busy clinical settings since it omits joint examination. Furthermore, it can provide more objective information compared to PROs since it does not contain any parameter on patients' perception of well-being. Hence, it is known that fibromyalgia which accompanies RA approximately in up to one in seven cases may affect expression of disease activity in RA patients negatively. Therefore, DAS28-ESR values and PROs should be regarded with caution in these patients. ${ }^{32,33}$ In a study comparing DAS28-ESR, CDAI, HAQ Disability Index and RAPID3 to evaluate disease activity in RA, it was noted that in areas where illiteracy is high, CDAI may be the preferred choice for assessment of disease activity. ${ }^{29}$ Therefore, CAR, an inflammation- based ratio, may also be an adjunctive measure for assessment of disease activity in such areas since it depends only on laboratory data omitting patients' own disease evaluation. The advantages suggesting CAR as a candidate for an adjunctive disease activity index may be its diminishing the time spent for joint examination in busy clinical settings and hampering possible overestimations due to patients' self-evaluation.

Serum RF titers are known to display significant association with disease activity and DAS28 score. ${ }^{34}$ Also, high titers of RF were reported to be a poor prognostic factor and a predictor of resistance to therapy in RA. ${ }^{35}$ In recent studies, high titers of both RF and ACPAs were reported to be associated with increased circulating tumor necrosis-alpha levels and reduced clinical responses. ${ }^{36}$ Therefore, the weak but significant correlation we observed between CAR and RF titer in the seropositive group is in accordance with the literature substantiating the role of CAR as an adjunctive disease activity marker.

The strong element of this study is the investigation of the relationship between CAR and RA disease activity, functional status, and QoL in a cross sectional design for the first time. Our results are similar to the first retrospective study observing a positive correlation between DAS28-ESR score and CAR in the literature. ${ }^{11}$ However, a limitation of the current study was the lack of evaluating the relationship between CAR and other disease activity indices such as CDAI and SDAI. Also, CAR's sensitivity to change may be studied in a prospective setting. The role of CAR in other rheumatologic conditions may be investigated in further studies. Moreover, it would have been better if fatigue, which is regarded as an extraarticular manifestation among patients with RA, was evaluated with a validated scale for RA such as the Functional Assessment of Chronic Illness Therapy to obtain more reliable and diseasespecific results. ${ }^{37}$

In conclusion, we found a positive weak correlation between CAR and DAS28-ESR, $\mathrm{ESR}$, and the RF titer suggesting the potential role of $\mathrm{CAR}$ as an additional index to assess systemic inflammation in patients with RA. Further studies are required to determine the utility of CAR in RA. 


\section{Declaration of conflicting interests}

The authors declared no conflicts of interest with respect to the authorship and/or publication of this article.

\section{Funding}

The authors received no financial support for the research and/or authorship of this article.

\section{REFERENCES}

1. Aletaha D, Smolen JS. Diagnosis and Management of Rheumatoid Arthritis: A Review. JAMA 2018;320:1360-72.

2. Goekoop-Ruiterman YP, de Vries-Bouwstra JK, Allaart CF, van Zeben D, Kerstens PJ, Hazes JM, et al. Clinical and radiographic outcomes of four different treatment strategies in patients with early rheumatoid arthritis (the BeSt study): a randomized, controlled trial. Arthritis Rheum 2005;52:3381-90.

3. Nakken B, Papp G, Bosnes V, Zeher M, Nagy G, Szodoray P. Biomarkers for rheumatoid arthritis: From molecular processes to diagnostic applications-current concepts and future perspectives. Immunol Lett 2017;189:13-18.

4. Fransen J, van Riel PL. The Disease Activity Score and the EULAR response criteria. Rheum Dis Clin North Am 2009;35:745-57.

5. Smolen JS, Aletaha D, Bijlsma JW, Breedveld FC, Boumpas D, Burmester G, et al. Treating rheumatoid arthritis to target: recommendations of an international task force. Ann Rheum Dis 2010;69:631-7.

6. Kalyoncu U, Dougados M, Daurès JP, Gossec L. Reporting of patient-reported outcomes in recent trials in rheumatoid arthritis: a systematic literature review. Ann Rheum Dis 2009;68:183-90.

7. Aletaha D, Nell VP, Stamm T, Uffmann M, Pflugbeil $\mathrm{S}$, Machold $\mathrm{K}$, et al. Acute phase reactants add little to composite disease activity indices for rheumatoid arthritis: validation of a clinical activity score. Arthritis Res Ther 2005;7:796-806.

8. Castell JV, Gómez-Lechón MJ, David M, Fabra R, Trullenque R, Heinrich PC. Acute-phase response of human hepatocytes: regulation of acute-phase protein synthesis by interleukin-6. Hepatology 1990;12:1179-86.

9. Yildirim K, Karatay S, Melikoglu MA, Gureser G, Ugur M, Senel K. Associations between acute phase reactant levels and disease activity score (DAS28) in patients with rheumatoid arthritis. Ann Clin Lab Sci 2004;34:423-6.

10. Deng TB, Zhang J, Zhou YZ, Li WM. The prognostic value of $\mathrm{C}$-reactive protein to albumin ratio in patients with lung cancer. Medicine (Baltimore) 2018;97:e13505.

11. Yang WM, Zhang WH, Ying HQ, Xu YM, Zhang $\mathrm{J}$, Min $\mathrm{QH}$, et al. Two new inflammatory markers associated with disease activity score-28 in patients with rheumatoid arthritis: Albumin to fibrinogen ratio and $\mathrm{C}$-reactive protein to albumin ratio. Int Immunopharmacol 2018;62:293-8.

12. Prevoo ML, van 't Hof MA, Kuper HH, van Leeuwen MA, van de Putte LB, van Riel PL. Modified disease activity scores that include twenty-eight-joint counts. Development and validation in a prospective longitudinal study of patients with rheumatoid arthritis. Arthritis Rheum 1995;38:44-8.

13. Whalley D, McKenna SP, de Jong Z, van der Heijde D. Quality of life in rheumatoid arthritis. Br J Rheumatol 1997;36:884-8.

14. Kutlay S, Küçükdeveci AA, Gönül D, Tennant A. Adaptation and validation of the Turkish version of the Rheumatoid Arthritis Quality of Life Scale. Rheumatol Int 2003;23:21-6.

15. Küçükdeveci AA, Sahin H, Ataman S, Griffiths B, Tennant A. Issues in cross-cultural validity: example from the adaptation, reliability, and validity testing of a Turkish version of the Stanford Health Assessment Questionnaire. Arthritis Rheum 2004;51:14-9.

16. Fries JF, Spitz P, Kraines RG, Holman HR. Measurement of patient outcome in arthritis. Arthritis Rheum 1980;23:137-45.

17. Akoglu H. User's guide to correlation coefficients. Turk J Emerg Med 2018;18:91-93.

18. Wu CC, Li SH, Lu HI, Lo CM, Wang YM, Chou SY, et al. Inflammation-based prognostic scores predict the prognosis of locally advanced cervical esophageal squamous cell carcinoma patients receiving curative concurrent chemoradiotherapy: a propensity scorematched analysis. PeerJ 2018;6:5655.

19. Guo Y, Cai K, Mao S, Zhang J, Wang L, Zhang Z, et al. Preoperative $\mathrm{C}$-reactive protein/albumin ratio is a significant predictor of survival in bladder cancer patients after radical cystectomy: a retrospective study. Cancer Manag Res 2018;10:4789-804.

20. Mao M, Wei X, Sheng H, Chi P, Liu Y, Huang X, et al. C-reactive protein/albumin and neutrophil/ lymphocyte ratios and their combination predict overall survival in patients with gastric cancer. Oncol Lett 2017;14:7417-24.

21. Qin G, Tu J, Liu L, Luo L, Wu J, Tao L, et al. Serum albumin and c-reactive protein/albumin ratio are useful biomarkers of Crohn's disease activity. Med Sci Monit 2016;22:4393-4400.

22. Moon JS, Ahn SS, Park YB, Lee SK, Lee SW. C-Reactive Protein to Serum Albumin Ratio Is an Independent Predictor of All-Cause Mortality in Patients with ANCA-Associated Vasculitis. Yonsei Med J 2018;59:865-71.

23. Ranzani OT, Zampieri FG, Forte DN, Azevedo LC, Park M. C-reactive protein/albumin ratio predicts 90-day mortality of septic patients. PLoS One 2013;8:e59321.

24. Oh TK, Song IA, Lee JH. Clinical usefulness of C-reactive protein to albumin ratio in predicting 30-day 
mortality in critically ill patients: A retrospective analysis. Sci Rep 2018;8:14977.

25. Bruschi M, Candiano G, Santucci L, Ghiggeri GM. Oxidized albumin. The long way of a protein of uncertain function. Biochim Biophys Acta 2013;1830:5473-9.

26. Seringec Akkececi N, Yildirim Cetin G, Gogebakan H, Acipayam C. The C-Reactive Protein/Albumin Ratio and Complete Blood Count Parameters as Indicators of Disease Activity in Patients with Takayasu Arteritis. Med Sci Monit 2019;25:1401-9.

27. Garip Y, Eser F, Bodur H. Health-related quality of life in rheumatoid arthritis: comparison of RAQoL with other scales in terms of disease activity, severity of pain, and functional status. Rheumatol Int 2011;31:769-72.

28. MaskaL, Anderson J, MichaudK. Measures of functional status and quality of life in rheumatoid arthritis: Health Assessment Questionnaire Disability Index (HAQ), Modified Health Assessment Questionnaire (MHAQ), Multidimensional Health Assessment Questionnaire (MDHAQ), Health Assessment Questionnaire II (HAQ-II), Improved Health Assessment Questionnaire (Improved HAQ), and Rheumatoid Arthritis Quality of Life (RAQoL). Arthritis Care Res (Hoboken) 2011;63 Suppl 11:S4-13.

29. Kumar BS, Suneetha P, Mohan A, Kumar DP, Sarma KVS. Comparison of Disease Activity Score in 28 joints with ESR (DAS28), Clinical Disease Activity Index (CDAI), Health Assessment Questionnaire Disability Index (HAQ-DI) \& Routine Assessment of Patient Index Data with 3 measures (RAPID3) for assessing disease activity in patients with rheumatoid arthritis at initial presentation. Indian $\mathrm{J}$ Med Res 2017; 146:57-62.

30. Leeb BF, Haindl PM, Brezinschek HP, Nothnagl T,
Rintelen B. RADAI-5 to monitor rheumatoid arthritis. Clin Exp Rheumatol. 2014;32(5 Suppl 85):S-55-8.

31. Leeb BF, Sautner J, Mai HT, Haindl PM, Deutsch C, Rintelen B. A comparison of patient questionnaires and composite indexes in routine care of rheumatoid arthritis patients. Joint Bone Spine 2009;76:658-64.

32. Leeb BF, Andel I, Sautner J, Nothnagl T, Rintelen B. The DAS28 in rheumatoid arthritis and fibromyalgia patients. Rheumatology (Oxford) 2004;43:1504-7.

33. Singh H, Tanwar V, Sukhija G, Mathur R, Kaur P. Rheumatoid arthritis disease activity index-5: Utility in busy clinical settings. Indian Journal of Rheumatology 2017;12:72-5.

34. Choe JY, Bae J, Lee H, Bae SC, Kim SK. Relation of rheumatoid factor and anti-cyclic citrullinated peptide antibody with disease activity in rheumatoid arthritis: cross-sectional study. Rheumatol Int 2013;33:2373-9.

35. Takayoshi Owada KK, Takamura Y, Namiki Y, Tanaka A, Yamazaki R, Okada H, etal. Change in RF Titers Reflects RA Disease Activity and Predicts Therapeutic Response during TNF Inhibitor Therapy; Patients with a Continuous Reduction of Serum RF Levels Show Good Response. 2015 ACR/ARHP Annual Meeting: Arthritis Rheumatol. 2015;67(Suppl 10);501.

36. Takeuchi T, Miyasaka N, Inui T, Yano T, Yoshinari $\mathrm{T}$, Abe $\mathrm{T}$, et al. High titers of both rheumatoid factor and anti-CCP antibodies at baseline in patients with rheumatoid arthritis are associated with increased circulating baseline TNF level, low drug levels, and reduced clinical responses: a post hoc analysis of the RISING study. Arthritis Res Ther 2017;19:194.

37. Cella D, Yount S, Sorensen M, Chartash E, Sengupta N, Grober J. Validation of the Functional Assessment of Chronic Illness Therapy Fatigue Scale relative to other instrumentation in patients with rheumatoid arthritis. J Rheumatol 2005;32:811-9. 